Review

\title{
Antibiotics in aquatic environments of China: A review and meta-analysis
}

\author{
Zhen $\mathrm{Li}^{\mathrm{a}}$, Miao $\mathrm{Li}^{\mathrm{a}, * *}$, Zhenya Zhang ${ }^{\mathrm{b}}$, Peng $\mathrm{Li}^{\mathrm{c}}$, Yongge Zang ${ }^{\mathrm{a}}$, Xiang Liu ${ }^{\mathrm{a}, *}$ \\ ${ }^{\text {a }}$ School of Environment, Tsinghua University, Beijing, 100084, China \\ ${ }^{\mathrm{b}}$ Graduate School of Life and Environmental Sciences, University of Tsukuba, 1-1-1 Tennodai, Tsukuba, Ibaraki, 305-8572, Japan \\ ${ }^{\mathrm{c}}$ Beijing Institute of Hydrogeology and Engineering Geology, Beijing, 100195, China
}

\section{A R T I C L E I N F O}

\section{Keywords:}

Antibiotics

Aquatic environments

Occurrence

China

Surface water

Groundwater

\begin{abstract}
A B S T R A C T
Antibiotics have adverse effects on human health and aquatic ecosystems in water environment, which is the main pool. In this study, antibiotics in the aquatic environment of China, containing both surface water and groundwater, were first systematically reviewed. That is essential for surface water and groundwater guideline and industry management. 128 articles were reviewed, containing 116 papers on surface water and 12 papers on groundwater. 94 antibiotics were detected at least once in the aquatic environment of China and most of the studies were in the eastern areas of China. The median concentrations of most antibiotics were below than $100 \mathrm{ng} / \mathrm{L}$ in the surface water and $10 \mathrm{ng} / \mathrm{L}$ in the groundwater. The concentrations of most antibiotics in China were similar or a little higher than in other countries. According to risk assessment, three antibiotics (enrofloxacin, ofloxacin and erythromycin) and three regions (Haihe River, Wangyang River and Taihu Lake) should be given more concerns. Strengthened policy and management are needed in these regions. In the future, more studies on groundwater and a priority list of antibiotics in the aquatic environment was needed.
\end{abstract}

\section{Introduction}

Antibiotics are emerging environmental pollutants, and due to the overuse and misuse, the prevalence and persistence of antibiotics have been an issue of global concern. However, $70 \%-90 \%$ of antibiotics are excreted unchanged or in active metabolites (Masse et al., 2014). Due to limited removal rates of wastewater treatment plants, large amounts of antibiotics have been transferred from effluent into surface water, groundwater, and even drinking water (Jurado et al., 2019; Sharma et al., 2019). The residual antibiotics in the environments were potentially serious threats to human health and ecosystems (Fekadu et al., 2019) and lead to the generation and spread of antibiotics resistance genes and antibiotics resistance bacteria, which could transferred into pathogens and transmit from the natural environment to human bodies (Perry and Wright, 2013), causing more serious threats.

Currently, researchers have carried out plenty of studies on the detection methods, occurrence, fate, ecological toxicity andremoval of antibiotics. Firstly, in the last years, many reviewers have compiled data on the distribution of antibiotics in wastewater (Szymanska et al., 2019), surface waters (Bilal et al., 2020; Danner et al., 2019), lakes (Cheng et al., 2018; Liu et al., 2018a), seas (Li et al., 2018b), groundwater (Dong et al., 2018), soil (Rusu et al., 2015), food (Done and Halden, 2015) and so on. Aquatic environment is the major pool for antibiotics. The antibiotics will recharged into aquatic environment by effluent discharge after treatments, surface runoff and other ways. Secondly, some researchers summarized antibiotics in aquatic environments for different kinds of antibiotics, for examples, fluoroquinolone antibiotics (Riaz et al., 2018; Taveira Parente et al., 2019) and cephalosporin antibiotics (Ribeiro et al., 2018). Thirdly, these reviews were accounted for global regions (Cheng et al., 2018), specific regions, such as European (Carvalho and Santos, 2016) and African (Fekadu et al., 2019), specific countries and even major rivers (Guan et al., 2017). China is the largest producer and user of antibiotics in the world (Zhu et al., 2013). The usage of all the antibiotics in most of China in 2013 was 162, $000 \mathrm{t}$ (Zhang et al., 2015).

In the past five years, three reviews were carried out on the distribution of antibiotics in aquatic environments of China. Liu et al. (2018b) had summarized the occurrence of antibiotics in water, sediment and aquatic organisms of typical lakes and quinolone antibiotics pose the greatest risks. Li et al. (2018b) had reviewed 94 antibiotics in seven China's major rivers and four seas from 2005 to 2016 and the highest median concentrations were found in water and sediments of Hai River. Zhao et al. (2016) had discussed the pharmaceuticals and personal care products (containing antibiotics) in the surface water and sediments of China during 2012-2015. Also, groundwater is an important source of drinking water for most of the regions of China. Sui

\footnotetext{
* Corresponding author.

** Corresponding author.

E-mail addresses: miaoli@tsinghua.edu.cn (M. Li), x.liu@tsinghua.edu.cn (X. Liu).
} 
et al. (2015) had reviewed the pharmaceuticals and personal care products (containing antibiotics) in the groundwater of all over the world during 2012-2014. However, no comprehensive review of antibiotics in surface water and groundwater of China was conducted.

In our study, we gathered the occurrence and distribution of antibiotics in aquatic environments of China, containing surface water (rivers, lakes, reservoir and pond) and groundwater. The objectives were to (1) understand temporal and spatial distributions of all previous work; (2) identify antibiotics with high concentrations through a meta-analysis and prioritize antibiotics with potential ecological risk; (3) examine the spatial distributions of representative antibiotic and the difference in surface water of China and other countries.

\section{Methods}

\subsection{Data collection}

This study was based on reports carried out in China and published until 31 July 2019. The literature survey was conducted via searching in the Web of Knowledge using "China", "occurrence * OR determination * OR detection * OR distribution *", "water" and "antibiotics * OR antibiotic *" as the topics. Publications were checked individually to eliminate any irrelevant articles and also which failed to provide specific values were abandoned.

\subsection{Statistical analysis}

The mean and maximum concentrations of antibiotics were either collected from the publications or calculated using the data provided in the publications. The concentrations those were reported as "not detected" or "below detection limit" were assigned a value of zero (Li et al., 2018d). Referred to the meta-analysis methods (Cheng et al., 2018), the concentration values from the same sites in two years were considered as different data entries and from different seasons in a successive year were calculated for the mean value.

\subsection{Risk assessment}

Ecotoxicological risk was assessed based on the risk quotients (RQ) value, as shown in Equation (1). Worst case assumptions were considered and the highest concentration of the antibiotic was adopted as the values for the measured environmental concentration (MEC). The predicted no-effect concentration (PNEC) of antibiotic was estimated using the acute half maximal effective concentration $\left(\mathrm{EC}_{50}\right)$ or half maximal lethal concentration ( $\mathrm{LC}_{50}$ ) divided by a default assessment factor (Li et al., 2015).

$$
\mathrm{RQ}=\mathrm{MEC} / \mathrm{PNEC}
$$

where,

$\mathrm{PNEC}=\left(\mathrm{EC}_{50}\right.$ or $\left.\mathrm{LC}_{50}\right) / 1000$

\section{Occurrence and concentrations of antibiotics in aquatic environments of China}

\subsection{Overview and scope}

Reports were searched in the Web of Knowledge and 539 publications were got. These publications were examined individually and further eliminated the irrelevant articles, such as the reports focusing on sea water, drinking water and tap water. Finally 128 articles met the requirements, 116 of which were on surface water and 12 were on groundwater, listed in Tables $1 \mathrm{~S}$ and $2 \mathrm{~S}$

Due to degradation and adsorption behavior of antibiotics in waters,
Table 1

The number of studies and detected number of each class of antibiotics in aquatic environments of China.

\begin{tabular}{lllll}
\hline & \multicolumn{2}{l}{ Surface water } & \multicolumn{2}{l}{ Groundwater } \\
\cline { 2 - 5 } & $\mathrm{N}^{\mathrm{a}}$ & $\mathrm{n}^{\mathrm{b}}$ & $\mathrm{N}$ & $\mathrm{n}$ \\
\hline Sulfonamides & 57 & 27 & 5 & 16 \\
Quinolones & 50 & 23 & 5 & 15 \\
Telracyclies & 46 & 8 & 4 & 4 \\
Macrolides & 40 & 11 & 5 & 6 \\
B-lactam & 6 & 11 & 0 & 0 \\
Chloramphenicols & 22 & 5 & 2 & 2 \\
Others & 17 & 9 & 1 & 2 \\
\hline
\end{tabular}

Notes.

a Number of studies.

b Number of studied compounds.

the antibiotics in waters may vary and the articles in the past five years (2014-2019) were overviewed for the concentrations and risk assessment of antibiotics in waters. Data was extracted from these articles to develop a database, including compound name, sampling location, concentration, and reference information. Articles which failed to provide specific values were abandoned. However, due to different measurement techniques used, there were data errors induced by the numeric or measurement techniques, which were not considered.

There were 94 antibiotics reported in more than one article in the past five years. As shown in Table 1, these 94 antibiotics were classified as sulfonamides, quinolones, telracyclies, macrolides, $\beta$-lactam, chloramphenicols and other antibiotics. Sulfonamides and quinolones were the most commonly investigated antibiotics in the surface water and groundwater of China and that may be related to the degradation and adsorption behaviors of antibiotics in water (Cheng et al., 2018). Also, among sulfonamides and quinolones, more antibiotics were contained and 27 sulfonamides and 23 quinolones antibiotics were reported in the surface water, while 16 sulfonamides and 15 quinolones antibiotics were studied in the groundwater, respectively. Telracyclies (8) and chloramphenicols (5) antibiotics contained in these articles were least. However, telracyclies were reported in $68.66 \%$ articles about surface water. In the groundwater, sulfonamides, quinolones, telracyclies and macrolides antibiotics were the four most commonly investigated antibiotics. $\beta$-lactam antibiotics had not been reported in the groundwater of China in the past five years. Sulfonamides and quinolones antibiotics were more extensively contained in the groundwater, which was the same as in the surface water.

\subsection{Temporal and spatial distribution of studies}

Fig. 1 shows the numbers of publications in every year for the occurrence of antibiotics in aquatic environments. Compared with surface water, groundwater was more difficulty to sample and antibiotics were harder to be detected in the groundwater (Li et al., 2014). So, more studies were on surface water $(90.63 \%)$ than those on groundwater $(9.38 \%)$ in aquatic environments of China. Also, reports on the occurrence of antibiotics in groundwater were posterior to surface water and as shown in Fig. 1, the studies on the occurrence of antibiotics in groundwater started in 2011.

Before 2007, no research was on the occurrence and concentrations of antibiotics in aquatic environments of China. The first study appeared in 2007. Xu et al. (2007) analyzed nine antibiotics in the Victoria Harbour of Hong Kong and the Pearl River of Guangzhou using high performance liquid chromatography-electrospray ionization tandem mass spectrometry. During the period of 2007-2010, less than three manuscripts on the occurrence of antibiotics in aquatic environments were published in every year and no publication was on groundwater. From 2011, more attentions were paid and at least seven manuscripts on the occurrence of antibiotics in aquatic environments 


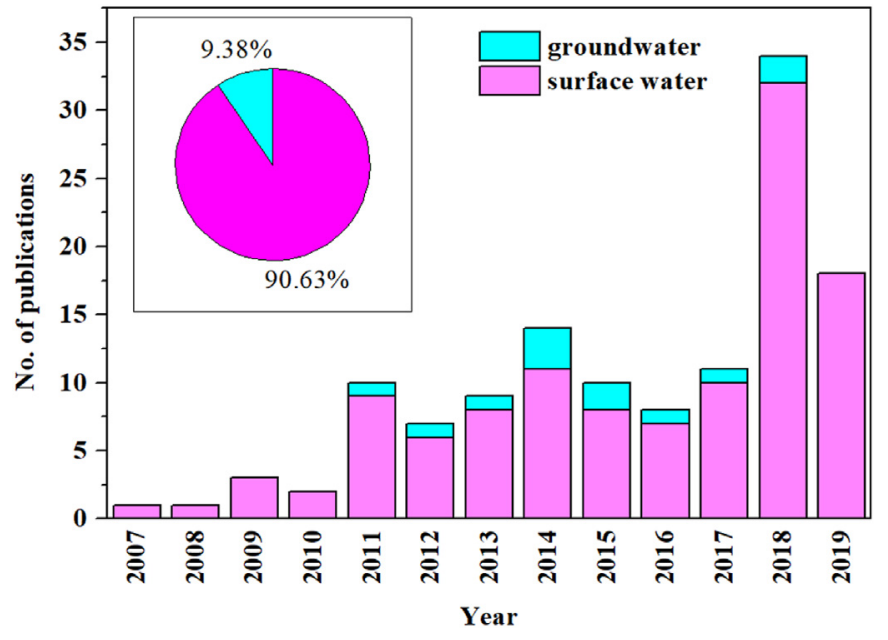

Fig. 1. No. of publications on antibiotics in aquatic environments of China.

were published in every year. In 2018, 34 publications were found, 32 publications were for surface water and 2 publications were on groundwater. Although, the articles published until 31 July 2019 were search, 18 publications were found. During 2018, 2019, there were 52 articles appeared, contributing $41 \%$ of the total researches. The increasing studies were most attributed to the growing attention and investment in the environmental protection of government and the development of sampling and detection technology (Meng et al., 2016).

The geographical distribution of the reported sampling locations was shown in Fig. 2. Among the 128 studies, except Macau and Taiwan, all the provinces were covered. As shown in Fig. 2, most of the studies were designed to detect antibiotics in aquatic environments of eastern China. The most studies were taken place in Guangdong, Beijing and
Jiangsu provinces, which were 23,22 and 18 articles, respectively. In the middle and western provinces of China, less than five studies were found. That was similar to previous researches on pharmaceuticals and personal care products in the aquatic environment (Bu et al., 2013a) and organic contaminants in the sewage sludge (Meng et al., 2016). That was related to the highest density of population and economic development. Intensive studies of antibiotics were found in surface waters of Yangtze River, Pearl River, Songhuajiang River, Liao River and Taihu Lake.

\subsection{Occurrence of antibiotics in the surface water of China}

Fig. 3A shows the median and confidence interval concentrations of antibiotics in the surface water of China and twenty-two antibiotics whose median concentrations were below zero were abandoned. Twenty-four antibiotics had median values that were $<1 \mathrm{ng} / \mathrm{L}$, the median concentrations of twenty-eight antibiotics were among 1 and $10 \mathrm{ng} / \mathrm{L}$, eighteen antibiotics were among 10 and $100 \mathrm{ng} / \mathrm{L}$ and two antibiotics (spectinomycin and streptomycin) were more than $100 \mathrm{ng} /$ L.

\subsubsection{Sulfonamides}

Table $3 \mathrm{~S}$ lists the concentration levels of sulfonamide antibiotics detected in surface water and the NO. of studies for sulfonamide antibiotics. Twenty-seven sulfonamides were reported at least once in the surface water in the last five years. Sulfamethoxazole (SMX) was the most studied sulfonamide antibiotic in the surface water and had been reported in 57 articles in the last five years, accounting for $85.07 \%$ of the total studies retrieved. The other three sulfonamides extensively detected were sulfadiazine (SDZ, 44), sulfamethazine (SMZ, 34) and trimethoprim (TMP, 34). As shown in Fig. 3 and Table 2, the median concentrations of SMX, sulfaquinoxaline (SQX) and TMP were higher than $5 \mathrm{ng} / \mathrm{L}$ in the surface water of China. That was similar with the

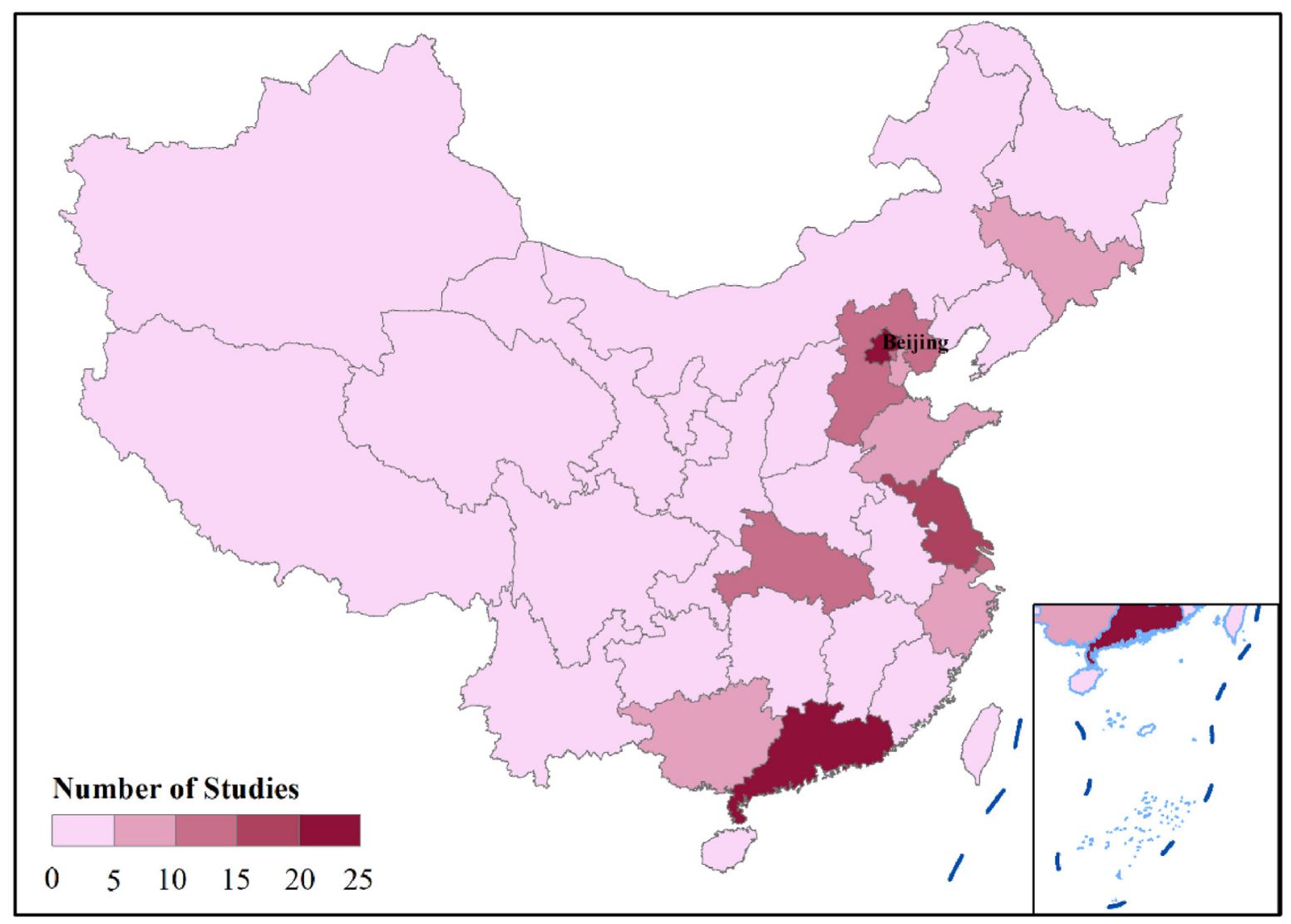

Fig. 2. National distribution of studies on antibiotics in aquatic environments of China. 
$\mathbf{A}$

tiamulin streptomycin spectinomycin ronidazole metridazole lincomycin thiamphenicol metronidazole flumequine florfenico chloramphenicol penicillin $\mathrm{V}$ penicillin $\mathbf{G}$ cephalexin cefotaxime cefazolin ampicillin amoxicillin

tylosin spiramycin roxithromycin oleandomycin kitasamycin erythromycin clarithromycin azithromycin tetracycline

oxytetracycline methacycline doxycycline chlortetracycline sparfloxacin sarafloxacin piromidic acid pipemidic acid pefloxacin oxolinic acid ofloxacin norfloxacin nalidixic acid moxifloxacin marbofloxacin

lomefloxacin levofloxacin gatifloxacin flumequine fleroxacin enrofloxacin enoxacin difloxacin danofloxacin ciprofloxacin cinoxacin trimethoprim sulfisoxazole sulfathiazole sulfaquinoxaline sulfapyridine sulfanilamide sulfamoxol sulfamonomethoxine sulfamethoxazole sulfamethizole sulfamethazine sulfameter sulfaguanidine sulfadoxine sulfadimidine sulfadiazine sulfachloropyridazine sulfachinoxalin benzene sulfonamide

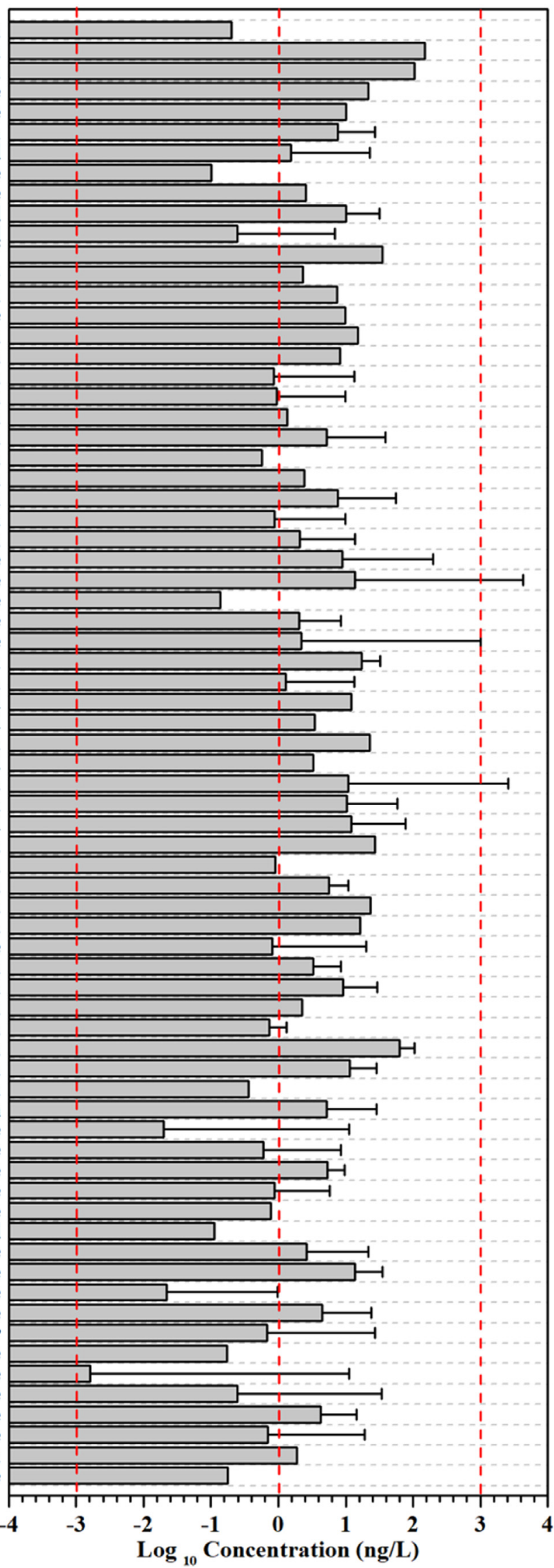

Fig. 3. Concentrations of antibiotics in the surface water (A) and groundwater (B) of China (median and 95\% confidence interval). 


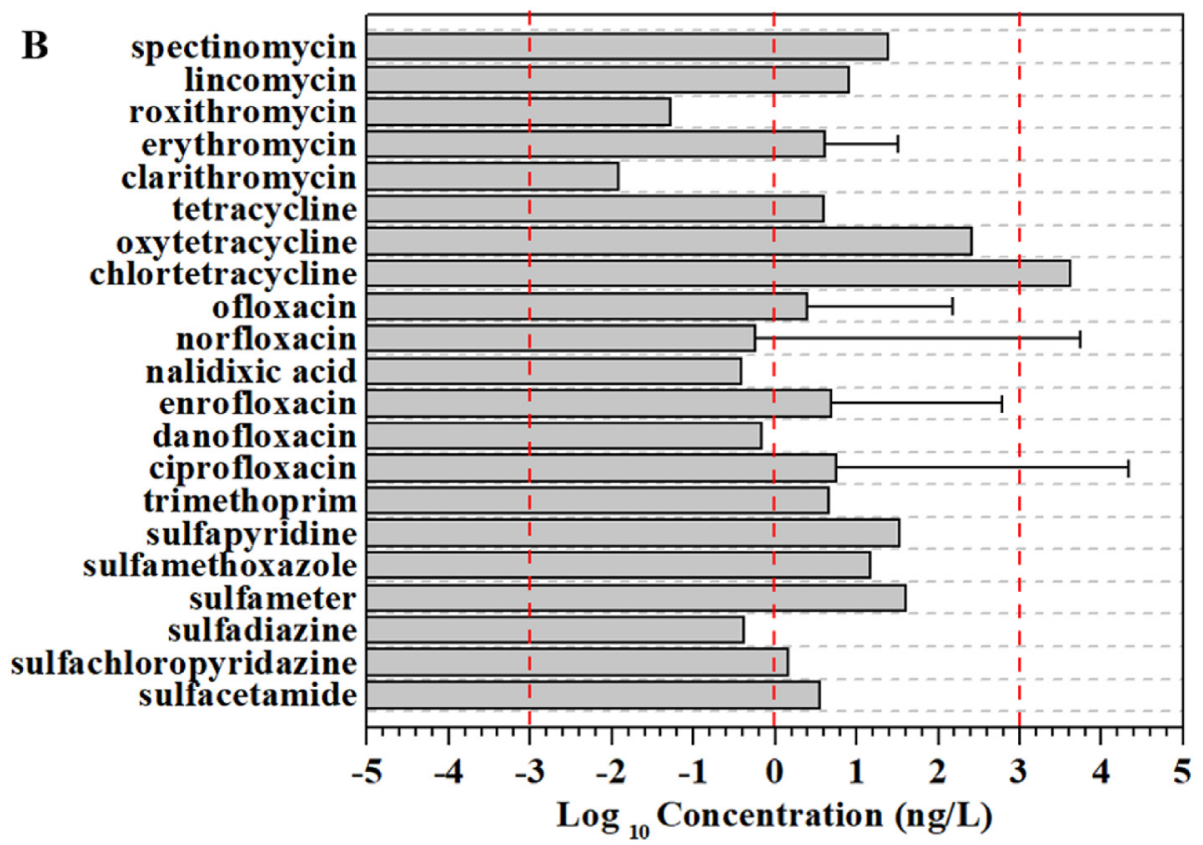

Fig. 3. (continued)

Table 2

Comparative analysis for the concentrations of SMX in other countries.

\begin{tabular}{|c|c|c|c|c|}
\hline Country & Site & Mean & Concentrations & Reference \\
\hline China & - & 35.18 & $0-4870$ & This study \\
\hline UK & Thames River & - & $10-35$ & White et al. (2019) \\
\hline Spain & Tagus river & 9.42 & $0-5962$ & Rico et al. (2019) \\
\hline Malaysia & Klang River & 0.21 & $0-0.86$ & Omar et al. (2019) \\
\hline France & Adour Estuary & - & $0-6.5$ & $\begin{array}{l}\text { Miossec et al. } \\
\text { (2019) }\end{array}$ \\
\hline \multirow[t]{3}{*}{ Malaysia } & Lui River & 51.49 & $19.25-75.48$ & \multirow{3}{*}{$\begin{array}{l}\text { Praveena et al. } \\
\text { (2018) }\end{array}$} \\
\hline & Gombak River & 100.55 & $95.81-109.34$ & \\
\hline & Selangor River & 95.53 & $84.31-114.24$ & \\
\hline Bangladesh & Brahmaputra River & 1.39 & $0-7.24$ & $\begin{array}{l}\text { Hossain et al. } \\
\text { (2018) }\end{array}$ \\
\hline Japan & $\begin{array}{l}\text { Yodo River } \\
\text { watershed }\end{array}$ & 11 & $5-18$ & $\begin{array}{l}\text { Hanamoto et al. } \\
\text { (2018) }\end{array}$ \\
\hline Vietnam & - & 259 & $0-2159$ & Chau et al. (2018) \\
\hline Canada & Red River & 3.49 & $1.5-7.6$ & $\begin{array}{l}\text { Challis et al. } \\
\text { (2018) }\end{array}$ \\
\hline Ghana & - & - & $13-2861$ & Azanu et al. (2018) \\
\hline Italy & Alpine rivers & 22.29 & $0-106.7$ & $\begin{array}{l}\text { Mandaric et al. } \\
\text { (2017) }\end{array}$ \\
\hline India & Gomti river & 0.59 & $1-3.5$ & $\begin{array}{l}\text { Hossain et al. } \\
\text { (2017) }\end{array}$ \\
\hline \multirow[t]{3}{*}{ Katari } & Urban area & 130 & $15-218$ & \multirow{3}{*}{$\begin{array}{l}\text { Archundia et al. } \\
\text { (2017) }\end{array}$} \\
\hline & Katari area & 24.2 & $18-31$ & \\
\hline & Cohana bay & 18.8 & $11.5-26$ & \\
\hline
\end{tabular}

retrieved results in the bulk water of global lakes and in that review, and SMX, sulfameter, TMP and sulfamerazine had the higher concentrations (median, > $11 \mathrm{ng} / \mathrm{L}$ ) (Cheng et al., 2018). The concentrations of SMX in China were similar to those in Ghana (13-2861 ng/L) (Azanu et al., 2018) and Mexico (76-2010 ng/L) (Rivera-Jaimes et al., 2018). The median concentration of SMZ in China was a little higher than in Spain (Galicia, 05-2.0 ng/L) (Iglesias et al., 2014). The median concentration of SMZ in China was similar to those in UK (River Thames, 3.4-350 ng/L) (White et al., 2019) and Bolivia (0-312 ng/L). The highest concentrations of sulfonamides were observed in Hai River (Chen et al., 2018b) and Wangyang River of Hebei province (Jiang et al., 2014).

\subsubsection{Quinolones}

Table 4S shows the concentration levels of quinolones detected in surface water and the NO. of studies for quinolones. Twenty-three quinolones were reported at least once in surface waters in the last five years. Ofloxacin (OFL) and ciprofloxacin (CIP) and norfloxacin (NOR) were studied most frequently and were reported in 50, 45 and 44 articles, respectively. The median concentrations of most quinolones were higher than most sulfonamides. As shown in Fig. 3A and Table 4S, the median concentrations of elven quinolones (accounting for $45.83 \%$ of the total quinolones) were higher than $10 \mathrm{ng} / \mathrm{L}$, seven quinolones were among 1 and $10 \mathrm{ng} / \mathrm{L}$ and only five quinolones were below than $1 \mathrm{ng} / \mathrm{L}$. The concentration of danofloxacin was highest, with the median concentration of $62.83 \mathrm{ng} / \mathrm{L}$, that was higher than the retrieved results in the bulk water of global lakes (median, < $1 \mathrm{ng} / \mathrm{L}$ ) (Cheng et al., 2018). The median concentrations of the three most frequently detected quinolones were among 10.36 and $11.44 \mathrm{ng} / \mathrm{L}$. The concentrations of CIP in the surface water of China were similar to those in Ghana (25-1168 ng/L) (Charuaud et al., 2019) and the concentrations of OFL, CIP and NOR were higher than those in Vietnam (Thai et al., 2018) and Europe (Szymanska et al., 2019). The maximum concentrations of OFL, CIP, NOR and enrofloxacin (ENR) were highest in Haihe river (Chen et al., 2018b), Yangtze River (Xu et al., 2019) and rural ponds of Hubei province (Chen et al., 2018a).

\subsubsection{Telracyclies}

Table $5 \mathrm{~S}$ shows the concentration levels of telracyclies detected in surface water and the NO. of studies for telracyclies. Eight telracyclies were reported at least once in the surface water of China in the last five years. Among the eight telracyclies, chlortetracycline (CTC), oxytetracycline (OTC) and tetracycline (TC) were the most detected telracyclies in the surface water of China, with the reports of 31, 46 and 45, respectively. The three telracyclies were frequently used for human and animals and the total usage of the three telracyclies was $3072 \mathrm{t}$ in 2013 (Zhang et al., 2015). Also, the levels of CTC, OTC and TC were highest, with the median concentrations of 2.2, 13.88 and $9.00 \mathrm{ng} / \mathrm{L}$ and maximum concentrations of $68900,361107.4$ and $25537 \mathrm{ng} / \mathrm{L}$, respectively. The highest concentrations of CTC, OTC and TC were observed in Wangyang River of Hebei province (Jiang et al., 2014). Those in the surface water of China were much higher than those in Korea (Kim et al., 2019), Africa and Europe (Fekadu et al., 2019) and Ghana (Azanu 
et al., 2018).

\subsubsection{Macrolides}

The concentration levels of macrolides detected in surface water and the NO. of studies for macrolides are shown Table 6S. Eleven macrolides were reported in the articles retrieved in the last five years and the median concentrations of five macrolides were higher than $1 \mathrm{ng} / \mathrm{L}$ (Fig. 3A). Erythromycin (ERY) and roxithromycin (ROX) were paid more attentions than other macrolides, with 40 and 39 related articles for the occurrence in the surface water of China, respectively. Also, the levels of ERY and ROX were highest, that was the same as telracyclies. The median concentrations of ERY and ROX were 7.61 and $5.22 \mathrm{ng} / \mathrm{L}$ and the highest concentrations were 4200 and $3700 \mathrm{ng} / \mathrm{L}$, respectively, observed in Haihe River (Chen et al., 2018b). Those concentrations of ERY in the surface water of China were lower than in UK (River Thames, 32-780 ng/L) (White et al., 2019), Iran (Tehran, $18.02 \mathrm{ng} / \mathrm{L}$ ) (Mirzaei et al., 2019) and Ghana (7.0-1149 ng/L) (Azanu et al., 2018) and higher than in Bangladesh (Old Brahmaputra river, 0-6.46 ng/L) (Hossain et al., 2018).

\subsection{5. $\beta$-lactam, chloramphenicols and others}

Table 7S shows the concentration levels of other antibiotics detected in surface water and the NO. of studies. There were eleven $\beta$-lactam antibiotics, five chloramphenicols and nine other antibiotics reported at least once in the last five years in the surface water of China. Compared with other groups of antibiotics, $\beta$-lactam antibiotics, chloramphenicols and other antibiotics were seldom reported. However, chloramphenicol (CAP) and florfenicol were most extensively reported, with 22 and 19 articles, respectively. The median concentration of florfenicol was more than $10 \mathrm{ng} / \mathrm{L}$ (Fig. 3A and Table 7S). The highest concentration of florfenicol was observed in river of Beijing-Tianjin-Hebei region for fish farming (Cheng et al., 2019). The median concentrations of part of antibiotics were more than $100 \mathrm{ng} / \mathrm{L}$, for example, spectinomycin and streptomycin, that were observed in Pearl river (Li et al., 2018a).

\subsection{Occurrence of antibiotics in the groundwater of China}

Fig. 3B and Tables 3S-7S show the occurrence of antibiotics in the groundwater of China in the last five years. The occurrence of antibiotics could be got from six articles. Forty-five antibiotics were reported at least once in the groundwater of China, including sixteen sulfonamides, fifteen quinolones, four telracyclies, six macrolides, two chloramphenicols and two others antibiotics. Six antibiotics (SMZ, CIP, ENR, NOR, OFL and ERY) were detected most frequently, with five articles for each antibiotic, followed by SMX, CTC, OTC and ROX. Those were similar with the reports for surface water and those antibiotics reported extensively had also been paid most attentions in the surface water.

Twenty-four antibiotics were not detected in the groundwater and abandoned in Fig. 3B. As shown in Fig. 3B, five antibiotics had median values that were $<1 \mathrm{ng} / \mathrm{L}$, the median concentrations of fifteen antibiotics were among 1 and $10 \mathrm{ng} / \mathrm{L}$ and one antibiotic (CTC) had median values that were $>10 \mathrm{ng} / \mathrm{L}$. The highest concentrations of CTC were observed in the groundwater of Beijng, Tianjin (Li et al., 2018c) and Hebei (Jiang et al., 2014), which were influenced by sewage effluent and pollution from swine feedlots. The maximum concentrations of other antibiotics were also observed in the groundwater of the three sites. The concentrations of antibiotics in the groundwater of China were higher than those in Korea ( 0 for SMZ, 0-0.52 ng/L for CIP, 0-0.19 ng/L for ENR, 0-1.27 for NOR and 0-0.70 for OFL) (Lee et al., 2019), Netherlands (not detected for CIP and ERY) (Kivits et al., 2018) and were lower than in Romania (relation to the proximity of urban area, 0-126.78 for NOR and 0-586.40 ng/L) (Szekeres et al., 2018) and Spain (Boy-Roura et al., 2018).

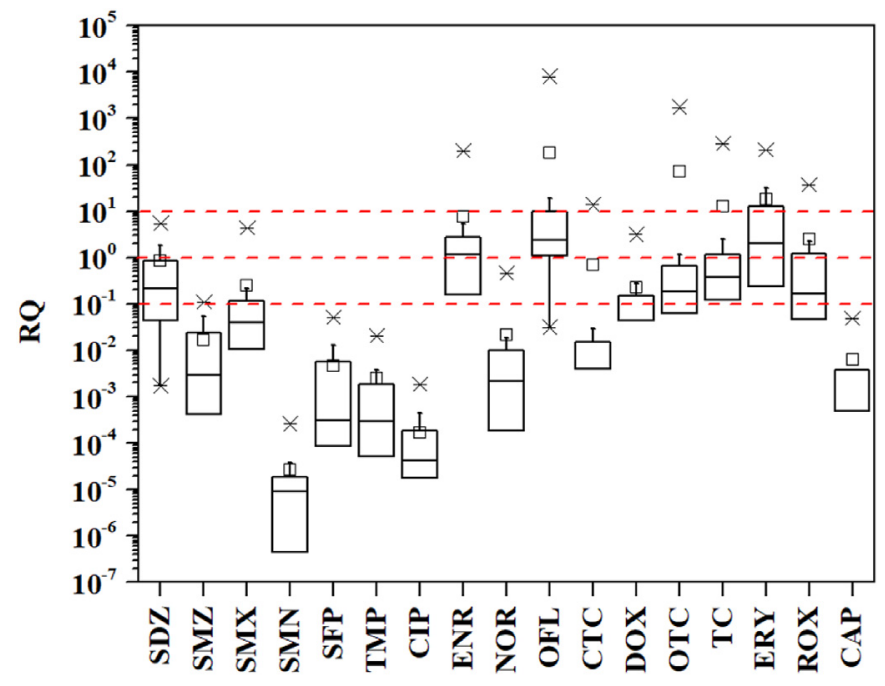

Fig. 4. Boxplots for the calculated RQs for the seventeen selected antibiotics detected in surface water of China.

\section{Risk assessment}

Exposure to antibiotics has adverse negative effects to organisms. In this study, the potential environmental risks of antibiotics to aquatic organisms were calculated, based on the RQs. Maximum concentrations of antibiotics in the aquatic environment of China were selected in order to consider the worst-case scenario. Due to less data of groundwater retrieved from former studies, the risk assessment of antibiotics in the surface water of China was only considered. Also, to reflect the overall risk of antibiotics in the surface water of China, the RQs were calculated for antibiotics reported frequently. These selected antibiotics were six sulfonamides (SDZ, SMZ, SMX, sulfamonomethoxine (SMN), SFP and TMP), four quinolones (CIP, ENR, NOR and OFL), four telracyclies (CTC, doxycycline (DOX), OTC and TC), two macrolides (ERY and ROX) and CAP. The PNECs of those antibiotics were collected from published studies and list in Table 8S.

The ranking criterion of RQs was applied $(\mathrm{RQ}<0.1$, insignificant risk; $0.1 \leq \mathrm{RQ}<1$, low risk; $1 \leq \mathrm{RQ}<10$; moderate risk; $\mathrm{RQ}>10$, high risk) (Agerstrand and Ruden, 2010). As shown in Fig. 4, SMN, SFP, TMP, CIP and CAP showed insignificant risk in the surface water of China. CTC, SMX, SMZ and NOR posed insignificant risk in $75 \%$ of the sampling sites, but CTC posed high risk, SMX showed moderate risk and SMZ and NOR showed low risk if considering the maximum concentration. For the other eight antibiotics, considering the median concentrations in the surface water of China, five antibiotics (SDZ, DOX, OTC, TC and ROX) posed low risk and three antibiotics (ENR, OFL and ERY) posed moderate risk. Except SDZ and DOX, the six antibiotics shows high risk in the sampling site with the maximum concentration. So in the future, we should pay more attentions on ENR, OFL and ERY in the surface water. The highest risks were observed in the river of Beijing-Tianjin-Hebei for ENR (Cheng et al., 2019), Haihe river for SMZ, SMX, OTC, TC, ERY and ROX (Chen et al., 2018b), two rural ponds of Hubei for OFL (Chen et al., 2018a) and Taihu Lake for DOX (Zhou et al., 2016). It is obvious that the Haihe River and the Taihu Lake should be regions of highly concern due to the high risks of antibiotics determined. These results could be used as references to the surface water and also groundwater guidelines. Furthermore, that could provide a basis for the industry management.

\section{Spatial variation and comparisons of SMX concentrations}

Due to the most studies, SMX was chosen as a representative antibiotic for the spatial variation of antibiotic nationally. The mean 


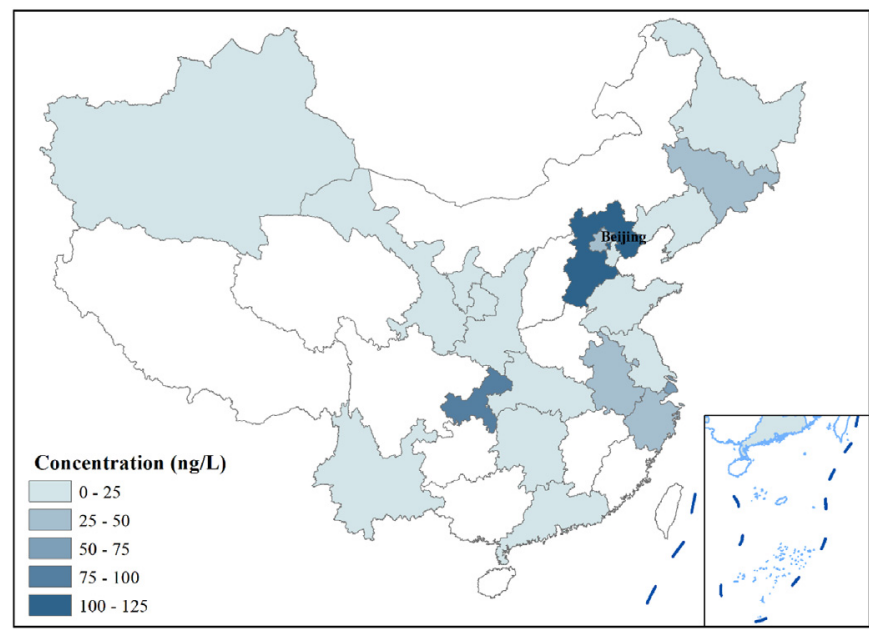

Fig. 5. Spatial variation of SMX in surface water of China.

concentrations of SMX in twenty-one province were calculated and the spatial variation of SMX in aquatic environments of China is shown in Fig. 5. The mean concentration of SMX in Hebei province (124.62 ng/L) was highest, followed by Chongqing (78.55 ng/L), Shanghai (58.01 ng/ $\mathrm{L})$, Beijing (42.58 ng/L) and Jilin (33.49 $\mathrm{ng} / \mathrm{L})$ province, that should be paid more attentions, especially Haihe River. These findings may have been related to differences in treatment technologies and usages among regions. Also, these results were similar with those of a previous study conducted by Bu et al. (2013b), in which higher PPCPs concentrations were shown to be related to higher population density in the adjacent cities, such as Beijing and Shanghai. The mean concentrations of SMX in other provinces retrieved were all lower than $25 \mathrm{ng} / \mathrm{L}$. In Shandong and Shanxi provinces and Hong Kong, the mean concentrations of SMX were lower than $5 \mathrm{ng} / \mathrm{L}$ and were 3.57, 3.75 and $1.1 \mathrm{ng} / \mathrm{L}$, respectively.

Also, as shown in Table 2, we compared the occurrence of SMX in the surface water of China with other countries. The mean concentration of SMX in the surface water of China was $35.18 \mathrm{ng} / \mathrm{L}$. Except Vietnam, Malaysia and India, there was small differences for the mean concentration of SMX between in the surface water of China and other countries. That was higher than most of studies in other countries retrieved, while lower than in Malaysia, Vietnam and Urban area of Katari. However, the maximum concentration of SMX in the surface water of China was much higher than other countries retrieved, except Spain and Ghana. The maximum concentration of SMX in the surface water of China was higher than Ghana and lower than Spain, but those were in the same order of magnitude. However, the maximum concentration of SMX in the surface water of China was 1-4 order of magnitude higher than other countries. Therefore, compared with other countries, the pollution of antibiotics in aquatic environments of China were serious. More attentions are needed to pay and correlative regulations are needed to restrict the sewage recharging. Also advanced technology in municipal wastewater treatment plant should be developed.

\section{Needs for antibiotics in aquatic environments of China}

The presence of antibiotics in aquatic environments is receiving increasing attentions. With the development of economics and increasing of population, the antibiotics emission and contamination will increase, which would pose risk to human being and ecology, therefore more attentions would be paid to antibiotics in the future, for example, the occurrence in the environment, transformation, the remove technology and so on.

Although a significant increase in the reports of antibiotics in the aquatic environment, four aspects on antibiotics in the aquatic environment should be paid more attentions. These four aspects were as follows,
Firstly, many studies have focused on the surface water and less has on the groundwater. In China, groundwater is the main resource of drinking water in many cities. Therefore, the quality of groundwater is much important for the health of human beings. Only 12 articles could be retrieved on the occurrence of antibiotics in the groundwater. In the future, the studies on groundwater need more attentions, especially the national distribution of antibiotics in the groundwater.

Secondly, most of the studies were on the occurrence of antibiotics in the eastern region and less were in the middle and western areas. Although the population in the middle and western areas was less than eastern areas and the development of economic was slower than eastern areas, studies are still needed.

Thirdly, due to the high risks, Haihe River, Wangyang River and Taihu Lake should be given more concerns. Also, the restrictions of swine wastewater and aquaculture sewage need to be strengthened. More guidelines are needed, such as surface water, groundwater, aquaculture sewage and so on.

Fourthly, 94 antibiotics were detected in the aquatic environment of China. However, many antibiotics, such as oxazolidinone and aminoglycoside antibiotics, have not yet been investigated in the aquatic environment of China. Also, the metabolites of antibiotics were not detected. Those may pose larger risk to human beings and ecosystem. Furthermore, as the developments of detection and new contaminants discovered, the database needs to be updated. A priority list of antibiotics in the aquatic environment is needed for detection in the future.

\section{Conclusion}

In this study, the distribution of antibiotics in aquatic environments of China, containing surface water and groundwater, were first systematically reviewed. That could provide guidance for the management of antibiotics in the aquatic environment. 128 articles were reviewed, including 116 on surface water and 12 on groundwater. 94 antibiotics were detected in the aquatic environments of China and sulfonamides and quinolones were paid more attentions with more kinds of antibiotics contained and more articles. Beginning in 2007, the studies on the distribution of antibiotics in the aquatic environment of China increased gradually and in 2018, 34 publications were retrieved. The median concentrations of most antibiotics were below than $100 \mathrm{ng} / \mathrm{L}$ and the median concentrations of SMX, danofloxacin, OTC and ERY were highest among sulfonamides, quinolones, telracyclies and macrolides in the surface water, respectively. The median concentrations of most antibiotics were below than $10 \mathrm{ng} / \mathrm{L}$ in the groundwater. Due to high risk, ENR, OFL and ERY should be paid more attention and Haihe River, Wangyang River and Taihu Lake should be given more concerns. In the future, more studies were needed on the groundwater and a priority list of antibiotics in the aquatic environment is needed.

\section{Declaration of competing interest}

No one.

\section{Acknowledgements}

The authors thank the China Postdoctoral Science Foundation (2018M631485) and Beijing Municipal Science and Technology Commission (Z181100005318002) for the financial support of this work.

\section{Appendix A. Supplementary data}

Supplementary data to this article can be found online at https:// doi.org/10.1016/j.ecoenv.2020.110668. 


\section{References}

Agerstrand, M., Ruden, C., 2010. Evaluation of the accuracy and consistency of the Swedish environmental classification and information system for pharmaceuticals. Sci. Total Environ. 408 (11), 2327-2339.

Archundia, D., Duwig, C., Lehembre, F., Chiron, S., Morel, M.C., Prado, B., BourdatDeschamps, M., Vince, E., Aviles, G.F., Martins, J.M.F., 2017. Antibiotic pollution in the Katari subcatchment of the Titicaca Lake: major transformation products and occurrence of resistance genes. Sci. Total Environ. 576, 671-682.

Azanu, D., Styrishave, B., Darko, G., Weisser, J.J., Abaidoo, R.C., 2018. Occurrence and risk assessment of antibiotics in water and lettuce in Ghana. Sci. Total Environ. 622, 293-305.

Bilal, M., Mehmood, S., Rasheed, T., Iqbal, H.M., 2020. Antibiotics traces in the aquatic environment: persistence and adverse environmental impact. Curr. Opin. Environ. Sci. Health $13,68-74$.

Boy-Roura, M., Mas-Pla, J., Petrovic, M., Gros, M., Soler, D., Brusi, D., Mencio, A., 2018. Towards the understanding of antibiotic occurrence and transport in groundwater: findings from the Baix Fluvia alluvial aquifer (NE Catalonia, Spain). Sci. Total Environ. 612, 1387-1406.

Bu, Q., Wang, B., Huang, J., Deng, S., Yu, G., 2013a. Pharmaceuticals and personal care products in the aquatic environment in China: a review. J. Hazard Mater. 262, 189-211.

Bu, Q.W., Wang, B., Huang, J., Deng, S.B., Yu, G., 2013b. Pharmaceuticals and personal care products in the aquatic environment in China: a review. J. Hazard Mater. 262, 189-211.

Carvalho, I.T., Santos, L., 2016. Antibiotics in the aquatic environments: a review of the European scenario. Environ. Int. 94, 736-757.

Challis, J.K., Cuscito, L.D., Joudan, S., Luong, K.H., Knapp, C.W., Hanson, M.L., Wong, C.S., 2018. Inputs, source apportionment, and transboundary transport of pesticides and other polar organic contaminants along the lower Red River, Manitoba, Canada. Sci. Total Environ. 635, 803-816.

Charuaud, L., Jarde, E., Jaffrezic, A., Thomas, M.F., Le Bot, B., 2019. Veterinary pharmaceutical residues from natural water to tap water: sales, occurrence and fate. J. Hazard Mater. 361, 169-186.

Chau, H.T.C., Kadokami, K., Duong, H.T., Kong, L., Nguyen, T.T., Nguyen, T.Q., Ito, Y. 2018. Occurrence of 1153 organic micropollutants in the aquatic environment of Vietnam. Environ. Sci. Pollut. Control Ser. 25 (8), 7147-7156.

Chen, D., Liu, S., Zhang, M., Li, S., Wang, J., 2018a. Comparison of the occurrence of antibiotic residues in two rural ponds: implication for ecopharmacovigilance. Environ. Monit. Assess. 190 (9).

Chen, H., Jing, L., Teng, Y., Wang, J., 2018b. Characterization of antibiotics in a largescale river system of China: occurrence pattern, spatiotemporal distribution and environmental risks. Sci. Total Environ. 618, 409-418.

Cheng, H., Yang, Y., Chen, Y., Chen, X., Cai, Z., Du, A., 2018. Novel monoclonal antibodybased immunochromatographic strip for detecting citrinin in fruit from Zhejiang province, China. PloS One 13 (5).

Cheng, J., Jiang, L., Sun, T., Tang, Y., Du, Z., Lee, L., Zhao, Q., 2019. Occurrence, seasonal variation and risk assessment of antibiotics in the surface water of north China. Arch. Environ. Contam. Toxicol. 77 (1), 88-97.

Danner, M.-C., Robertson, A., Behrends, V., Reiss, J., 2019. Antibiotic pollution in surface fresh waters: occurrence and effects. Sci. Total Environ. 664, 793-804.

Done, H.Y., Halden, R.U., 2015. Reconnaissance of 47 antibiotics and associated microbial risks in seafood sold in the United States. J. Hazard Mater. 282, 10-17.

Dong, W., Xie, W., Su, X., Wen, C., Cao, Z., Wan, Y., 2018. Review: micro-organic contaminants in groundwater in China. Hydrogeol. J. 26 (5), 1351-1369.

Fekadu, S., Alemayehu, E., Dewil, R., Van der Bruggen, B., 2019. Pharmaceuticals in freshwater aquatic environments: a comparison of the African and European challenge. Sci. Total Environ. 654, 324-337.

Guan, Y., Wang, B., Gao, Y., Liu, W., Zhao, X., Huang, X., Yu, J., 2017. Occurrence and fate of antibiotics in the aqueous environment and their removal by constructed wetlands in China: a review. Pedosphere 27 (1), 42-51.

Hanamoto, S., Nakada, N., Yamashita, N., Tanaka, H., 2018. Source estimation of pharmaceuticals based on catchment population and in-stream attenuation in Yodo River watershed, Japan. Sci. Total Environ. 615, 964-971.

Hossain, A., Nakamichi, S., Habibullah-Al-Mamun, M., Tani, K., Masunaga, S., Matsuda, H., 2017. Occurrence, distribution, ecological and resistance risks of antibiotics in surface water of finfish and shellfish aquaculture in Bangladesh. Chemosphere 188, 329-336.

Hossain, A., Nakamichi, S., Habibullah-Al-Mamun, M., Tani, K., Masunaga, S., Matsuda, H., 2018. Occurrence and ecological risk of pharmaceuticals in river surface water of Bangladesh. Environ. Res. 165, 258-266.

Iglesias, A., Nebot, C., Vazquez, B.I., Miranda, J.M., Abuin, C.M.F., Cepeda, A., 2014 Detection of veterinary drug residues in surface waters collected nearby farming areas in Galicia, North of Spain. Environ. Sci. Pollut. Control Ser. 21 (3), 2367-2377.

Jiang, Y., Li, M., Guo, C., An, D., Xu, J., Zhang, Y., Xi, B., 2014. Distribution and ecological risk of antibiotics in a typical effluent-receiving river (Wangyang River) in north China. Chemosphere 112, 267-274.

Jurado, A., Walther, M., Diaz-Cruz, M.S., 2019. Occurrence, fate and environmental risk assessment of the organic microcontaminants included in the Watch Lists set by EU Decisions 2015/495 and 2018/840 in the groundwater of Spain. Sci. Total Environ. 663, 285-296.

Kim, B., Ji, K., Kim, C., Kang, H., Lee, S., Kwon, B., Kho, Y., Park, K., Kim, K., Choi, K., 2019. Pharmaceutical residues in streams near concentrated animal feeding operations of Korea - occurrences and associated ecological risks. Sci. Total Environ. 655, 408-413.
Kivits, T., Broers, H.P., Beeltje, H., van Vliet, M., Griffioen, J., 2018. Presence and fate of veterinary antibiotics in age-dated groundwater in areas with intensive livestock farming. Environ. Pollut. 241, 988-998.

Lee, H.J., Kim, K.Y., Hamm, S.Y., Kim, M., Kim, H.K., Oh, J.E., 2019. Occurrence and distribution of pharmaceutical and personal care products, artificial sweeteners, and pesticides in groundwater from an agricultural area in Korea. Sci. Total Environ. 659, $168-176$.

Li, S., Shi, W., Li, H., Xu, N., Zhang, R., Chen, X., Sun, W., Wen, D., He, S., Pan, J., He, Z., Fan, Y., 2018a. Antibiotics in water and sediments of rivers and coastal area of Zhuhai City, Pearl River estuary, south China. Sci. Total Environ. 636, 1009-1019.

Li, S., Shi, W., Liu, W., Li, H., Zhang, W., Hu, J., Ke, Y., Sun, W., Ni, J., 2018b. A duodecennial national synthesis of antibiotics in China's major rivers and seas (20052016). Sci. Total Environ. 615, 906-917.

Li, X., Liu, C., Chen, Y., Huang, H., Ren, T., 2018c. Antibiotic residues in liquid manure from swine feedlot and their effects on nearby groundwater in regions of North China. Environ. Sci. Pollut. Control Ser. 25 (12), 11565-11575.

Li, Z., Li, M., Liu, X., Ma, Y., Wu, M., 2014. Identification of priority organic compounds in groundwater recharge of China. Sci. Total Environ. 493, 481-486.

Li, Z., Xiang, X., Li, M., Ma, Y.P., Wang, J.H., Liu, X., 2015. Occurrence and risk assessment of pharmaceuticals and personal care products and endocrine disrupting chemicals in reclaimed water and receiving groundwater in China. Ecotoxicol. Environ. Saf. 119, 74-80.

Li, Z., Zheng, T.L., Li, M., Liu, X., 2018d. Organic contaminants in the effluent of Chinese wastewater treatment plants. Environ. Sci. Pollut. Control Ser. 25 (27), 26852-26860.

Liu, X., Lu, S., Guo, W., Xi, B., Wang, W., 2018a. Antibiotics in the aquatic environments: a review of lakes, China. Sci. Total Environ. 627, 1195-1208.

Liu, X.H., Lu, S.Y., Guo, W., Xi, B.D., Wang, W.L., 2018b. Antibiotics in the aquatic environments: a review of lakes, China. Sci. Total Environ. 627, 1195-1208.

Mandaric, L., Diamantini, E., Stella, E., Cano-Paoli, K., Valle-Sistac, J., Molins-Delgado, D., Bellin, A., Chiogna, G., Majone, B., Diaz-Cruz, M.S., Sabater, S., Barcelo, D., Petrovic, M., 2017. Contamination sources and distribution patterns of pharmaceuticals and personal care products in Alpine rivers strongly affected by tourism. Sci. Total Environ. 590, 484-494.

Masse, D.I., Saady, N.M.C., Gilbert, Y., 2014. Potential of biological processes to eliminate antibiotics in livestock manure: an overview. Animals : Open Access J MDPI 4 (2), $146-163$.

Meng, X.-Z., Venkatesan, A.K., Ni, Y.-L., Steele, J.C., Wu, L.-L., Bignert, A., Bergman, A., Halden, R.U., 2016. Organic contaminants in Chinese sewage sludge: a meta-analysis of the literature of the past 30 years. Environ. Sci. Technol. 50 (11), 5454-5466.

Miossec, C., Lanceleur, L., Monperrus, M., 2019. Multi-residue analysis of 44 pharmaceutical compounds in environmental water samples by solid-phase extraction coupled to liquid chromatography-tandem mass spectrometry. J. Separ. Sci. 42 (10), 1853-1866.

Mirzaei, R., Mesdaghinia, A., Hoseini, S.S., Yunesian, M., 2019. Antibiotics in urban wastewater and rivers of Tehran, Iran: consumption, mass load, occurrence, and ecological risk. Chemosphere 221, 55-66.

Omar, T.F.T., Aris, A.Z., Yusoff, F.M., Mustafa, S., 2019. Risk assessment of pharmaceutically active compounds (PhACs) in the Klang River estuary, Malaysia. Environ. Geochem. Health 41 (1), 211-223.

Perry, J.A., Wright, G.D., 2013. The antibiotic resistance "mobilome": searching for the link between environment and clinic. Front. Microbiol. 4.

Praveena, S.M., Shaifuddin, S.N.M., Sukiman, S., Nasir, F.A.M., Hanafi, Z., Kamarudin, N., Ismail, T.H.T., Aris, A.Z., 2018. Pharmaceuticals residues in selected tropical surface water bodies from Selangor (Malaysia): occurrence and potential risk assessments. Sci. Total Environ. 642, 230-240.

Riaz, L., Mahmood, T., Khalid, A., Rashid, A., Siddique, M.B.A., Kamal, A., Coyne, M.S. 2018. Fluoroquinolones (FQs) in the environment: a review on their abundance, sorption and toxicity in soil. Chemosphere 191, 704-720.

Ribeiro, A.R., Sures, B., Schmidt, T.C., 2018. Cephalosporin antibiotics in the aquatic environment: a critical review of occurrence, fate, ecotoxicity and removal technologies. Environ. Pollut. 241, 1153-1166.

Rico, A., Arenas-Sanchez, A., Alonso-Alonso, C., Lopez-Heras, I., Nozal, L., Rivas-Tabares, D., Vighi, M., 2019. Identification of contaminants of concern in the upper Tagus river basin (central Spain). Part 1: screening, quantitative analysis and comparison of sampling methods. Sci. Total Environ. 666, 1058-1070.

Rivera-Jaimes, J.A., Postigo, C., Melgoza-Aleman, R.M., Acena, J., Barcelo, D., de Alda, M.L., 2018. Study of pharmaceuticals in surface and wastewater from Cuernavaca, Morelos, Mexico: occurrence and environmental risk assessment. Sci. Total Environ. 613, 1263-1274.

Rusu, A., Hancu, G., Uivarosi, V., 2015. Fluoroquinolone pollution of food, water and soil, and bacterial resistance. Environ. Chem. Lett. 13 (1), 21-36.

Sharma, B.M., Becanova, J., Scheringer, M., Sharma, A., Bharat, G.K., Whitehead, P.G., Klanova, J., Nizzetto, L., 2019. Health and ecological risk assessment of emerging contaminants (pharmaceuticals, personal care products, and artificial sweeteners) in surface and groundwater (drinking water) in the Ganges River Basin, India. Sci. Total Environ. 646, 1459-1467.

Sui, Q., Cao, X., Lu, S., Zhao, W., Qiu, Z., Yu, G., 2015. Occurrence, sources and fate of pharmaceuticals and personal care products in the groundwater: a review. Emerging Contaminants 1 (1), 14-24.

Szekeres, E., Chiriac, C.M., Baricz, A., Szoke-Nagy, T., Lung, I., Soran, M.L., Rudi, K., Dragos, N., Coman, C., 2018. Investigating antibiotics, antibiotic resistance genes, and microbial contaminants in groundwater in relation to the proximity of urban areas. Environ. Pollut. 236, 734-744.

Szymanska, U., Wiergowski, M., Soltyszewsk, I., Kuzemko, J., Wiergowska, G., Wozniak, M.K., 2019. Presence of antibiotics in the aquatic environment in Europe and their 
analytical monitoring: recent trends and perspectives. Microchem. J. 147, 729-740.

Taveira Parente, C.E., Souza Brito, E.M., Azeredo, A., Meire, R.O., Malm, O., 2019.

Fluoroquinolone antibiotics and their interactions in agricultural soils. Orbital -

Electron. J. Chem. 11 (1), 42-52.

Thai, P.K., Ky, L.X., Binh, V.N., Nhung, P.H., Nhan, P.T., Hieu, N.Q., Dang, N.T.T., Tam, N.K.B., Anh, N.T.K., 2018. Occurrence of antibiotic residues and antibiotic-resistant bacteria in effluents of pharmaceutical manufacturers and other sources around Hanoi, Vietnam. Sci. Total Environ. 645, 393-400.

White, D., Lapworth, D.J., Civil, W., Williams, P., 2019. Tracking changes in the occurrence and source of pharmaceuticals within the River Thames, UK; from source to sea. Environ. Pollut. 249, 257-266.

Xu, M., Huang, H., Li, N., Li, F., Wang, D., Luo, Q., 2019. Occurrence and ecological risk of pharmaceuticals and personal care products (PPCPs) and pesticides in typical surface watersheds, China. Ecotoxicol. Environ. Saf. 175, 289-298.

Xu, W.H., Zhang, G., Zou, S.C., Li, X.D., Liu, Y.C., 2007. Determination of selected antibiotics in the Victoria Harbour and the Pearl River, South China using high- performance liquid chromatography-electrospray ionization tandem mass spectrometry. Environ. Pollut. 145 (3), 672-679.

Zhang, Q.-Q., Ying, G.-G., Pan, C.-G., Liu, Y.-S., Zhao, J.-L., 2015. Comprehensive evaluation of antibiotics emission and fate in the river basins of China: source analysis, multimedia modeling, and linkage to bacterial resistance. Environ. Sci. Technol. 49 (11), 6772-6782

Zhao, W.T., Guo, Y., Lu, S.G., Yan, P.P., Sui, Q., 2016. Recent advances in pharmaceuticals and personal care products in the surface water and sediments in China. Front. Environ. Sci. Eng. 10 (6).

Zhou, L.-J., Wu, Q.L., Zhang, B.-B., Zhao, Y.-G., Zhao, B.-Y., 2016. Occurrence, spatiotemporal distribution, mass balance and ecological risks of antibiotics in subtropical shallow Lake Taihu, China. Environ. Sci. Process. Impacts 18 (4), 500-513.

Zhu, Y.-G., Johnson, T.A., Su, J.-Q., Qiao, M., Guo, G.-X., Stedtfeld, R.D., Hashsham, S.A., Tiedje, J.M., 2013. Diverse and abundant antibiotic resistance genes in Chinese swine farms. Proc. Natl. Acad. Sci. U. S. A 110 (9), 3435-3440. 